\title{
O PROFESSOR DE MATEMÁTICA E OS CONTEÚDOS DOS LIVROS DIDÁTICOS: DIZERES E FAZERES
}

\section{TEACHER OF MATHEMATICS AND THE CONTENT OF TEXTBOOKS: sayings and doings}

\author{
Vinícius Sanches Tizzo (G-UFMS) ${ }^{1}$ \\ Thiago Donda Rodrigues (UFMS/CPAR) ${ }^{2}$
}

\begin{abstract}
Resumo: Neste trabalho toma-se "utilização do livro didático" como um fenômeno a ser investigado, ou seja, busca-se alcançar a inteligibilidade em que o sentido desse fenômeno é articulado. Este trabalho tem como base uma pesquisa anterior fundamentada na fenomenologia e interessada em quais conteúdos o professor de matemática da rede de ensino público de Paranaíba - MS tem dificuldade de ensinar ou o aluno de aprender. Busca-se com esse estudo interpretar a coerência existente entre os discursos dos docentes, quanto à utilização do livro didático, e a manipulação dos conteúdos apresentados por este livro durante as aulas de matemática. É neste cenário que se insere a figura do professor entrevistado. Essa pesquisa baseou-se em entrevistas com professores, acompanhamento de suas aulas, análise de seus discursos e busca pela interpretação do que a este autor se manifestou. A intenção deste estudo é expor as informações prestadas por esses professores quanto à utilização do livro didático em sua prática pedagógica. Anseia-se, identificar razões, tanto nas entrevistas, como nas observações que justifiquem as dificuldades de utilização do livro didático em sala de aula. Embora o professor não apresente um aspecto específico que justifique a dificuldade de utilização do livro didático, continua a fazer uso do livro para a preparação das aulas. Logo, acredita-se que essas dificuldades são sanadas através do livro didático.
\end{abstract}

Palavras-chave: Livro didático de matemática. Discurso. Prática docente.

\begin{abstract}
In this work becomes "use of the textbook" as a phenomenon to be investigated, ie, we seek to achieve intelligibility in the sense that this phenomenon is articulated. This work builds on earlier research based on phenomenology and interested in what content the math teacher in public schools Paranaíba - MS is difficult to teach or student learning. Search this study is to interpret the coherence between the discourses of teachers, about the use of textbooks, and manipulation of content presented by this book during math classes. It is against this background that fits the figure of the teacher interview. This research was based on interviews with teachers, monitoring of their classes, analysis of his speeches and search for interpretation of what this author has manifested itself. The intent of this study is to reveal the information provided by these teachers on the use of textbooks in their teaching. Longs to identify reasons, both in interviews, as the observations that justify the difficulties of using the textbook in the classroom. Although the teacher does not present a specific aspect of the difficulty of justifying the use of textbooks, continues to use the book for the preparation of lessons. Therefore, it is believed that these difficulties are resolved through the textbook.
\end{abstract}

\footnotetext{
${ }^{1}$ Acadêmico do curso de matemática/UFMS/Paranaíba.

${ }^{2}$ Professor assistente do curso de licenciatura em matemática da Universidade Federal de mato Grosso do Sul, campus de Paranaíba - UFMS/CPAR.
} 
Keywords: Textbooks Math. Speech. teaching practice.

\section{Introdução}

Este estudo busca dar continuidade ao Plano de Trabalho "O professor de matemática e os conteúdos dos livros didáticos", que está sob responsabilidade de Vinícius Sanches Tizzo enquanto aluno voluntário de iniciação científica, PIBIC/UFMS/2008-2009 - e conta com a colaboração de integrantes do Grupo Matemática e Educação.

Considerando como questão geradora de pesquisa: quais os conteúdos que o professor de matemática da rede pública de ensino de Paranaíba-MS tem mais dificuldade de transmitir, ou o aluno de compreender, e como este professor utiliza o livro didático para suprir essas dificuldades? Busca-se expor as informações concedidas nas entrevistas, realizadas com professores da rede de ensino público de Paranaíba, e as observações feitas de cinco aulas de um desses professores.

Neste estudo, se mantêm a postura de buscar na fenomenologia (análise ideográfica) ${ }^{3}$ considerando Hiratsuka (2003), os dados necessários para a realização do estudo e também no que diz respeito à pesquisa qualitativa têm-se como referencial Lüdke e André (1986).

A opção de manter esse objetivo de estudo foi que, a partir das entrevistas percebese que a dificuldade dos professores entrevistados, quanto à utilização do livro didático, é mais acentuada do que se imagina, e por se julgar que este estudo contribuirá para com a formação dos acadêmicos a ele ligados, uma vez que terão a oportunidade de refletir sobre o tema antes de ingressar em sala de aula.

\section{Procedimentos metodológicos}

Tomando como referência os conteúdos que os professores de matemática da rede de ensino público de Paranaíba - MS têm dificuldade de ensinar, ou o aluno de aprender, o objetivo principal foi identificar a razão desta dificuldade.

Para tanto, entrevistas foram feitas com professores que tinham, em média, dez anos de experiência no ensino básico, possibilitando o acesso à vivência deste professor quanto à utilização do livro didático em sua prática pedagógica num período anterior ao da última seleção (2008). Também foram realizadas cinco observações das aulas de um dos educadores entrevistados, tomando sempre bastante cautela, pois, segundo Lüdke e André (1986), "para que se torne um instrumento válido e fidedigno de investigação científica, a observação precisa ser antes de tudo controlada e sistemática. Isso implica a existência de um planejamento cuidadoso do trabalho e uma preparação rigorosa do observador."

Antes de iniciar as observações, buscou-se, através do telefone, contato com um dos oito professores entrevistados anteriormente, tendo em vista o pouco tempo disponibilizado para a realização deste estudo. Do mais, precisou-se de um tempo para elaborar uma argumentação convincente, para que o professor permitisse a entrada em sala de aula, além do cuidado ao levantar os pontos a serem observados, isto porque,

\footnotetext{
${ }^{3}$ Interpretação de idéias.
}

\begin{tabular}{|l|l|l|l|l|l|}
\hline Interfaces da Educ. & Paranaíba & v. 2 & n. 5 & p.122-130 & 2011 \\
\hline
\end{tabular}


Planejar a observação significa determinar com antecedência "o que" e "o como" observar. A primeira tarefa, pois, no preparo das observações é a delimitação do objeto de estudo. Definindo-se claramente o foco da investigação e sua configuração espaço-temporal, ficam mais ou menos evidentes quais aspectos do problema serão cobertos pela observação e qual a melhor maneira de captá-los. (LÜDKE e ANDRÉ, 1986, p.25).

Buscou-se eleger o professor que mais se sentiu à vontade durante as entrevistas, entretanto, quando do início das observações foi constatado que este professor não está mais trabalhando com a disciplina de matemática, sendo assim, partiu-se em busca de outro entrevistado que não se constrangeria com a presença do pesquisador em sua sala de aula, deste modo, foi feita a escolha do professor João Carlos.

Faz-se importante frisar que esta pesquisa mantém compromisso assumido no decorrer das entrevistas de não divulgar a identidade do professor entrevistado, sendo esta uma das reivindicações dos professores para a realização das mesmas. Em conformidade com o sigilo das identidades dos entrevistados temos:

Há uma série de exigências e de cuidados requeridos por qualquer tipo de entrevista. Em primeiro lugar, um respeito muito grande pelo entrevistado. Esse respeito envolve desde um local e horário marcados e cumpridos de acordo com sua conveniência até a perfeita garantia do sigilo e anonimato em relação ao informante, se for o caso. (LÜDKE e ANDRÉ, 1986, p.35).

Com relação ao contato com o professor João Carlos, fez-se um aproveitamento das informações que anteriormente haviam sido levantadas, por conta da realização das entrevistas. $\mathrm{O}$ primeiro contato com o professor, na verdade serviu para elucidar a intenção de procurá-lo novamente. Esclareceu-se que esta observação serviria para complementar as entrevistas, anteriormente realizadas.

Entretanto, o professor que, de certo modo, não se sentiu tão à vontade em relação à pesquisa durante a entrevista, disse que não haveria problema em ter sua aula observada e justificou que, muitos estudantes lhe procuravam para fazer seus estágios, e, portanto, ele encararia esta observação desta forma.

Inclusive, nesta oportunidade reiteraram-se os intentos da pesquisa, e também foi entregue as transcrições das entrevistas, tanto a parte literal, quanto a entrevista com as unidades de significado selecionadas.

Quanto à definição de unidade de significado, temos:

[...] expressões que se destacaram como significativas quando da leitura de cada discurso sob o foco da interrogação [...]. As unidades de significado são, $\underline{a O S}$ olhos do pesquisador, unidades que expressam aspectos significativos da experiência vivida e, portanto, se inter-relacionam ao fazerem parte de uma trama real. (HIRATSUKA, 2003, p. 72-3) Grifos nossos.

Neste retorno da transcrição ao entrevistado, teve-se a oportunidade de contar com a colaboração da coordenadora da escola, que disponibilizou sua sala durante uma hora/aula para que o professor João Carlos falasse sobre a transcrição de sua entrevista. O professor fez a leitura da transcrição literal e sustentou os argumentos que usou quanto à dificuldade da utilização do livro didático.

Para uma melhor compreensão das informações concedidas pelo professor e a seleção das unidades de significado apresenta-se o roteiro e a transcrição na íntegra da entrevista com o professor João Carlos:

\begin{tabular}{|l|l|l|l|l|l|}
\hline Interfaces da Educ. & Paranaíba & v. 2 & n. 5 & p.122-130 & 2011 \\
\hline
\end{tabular}




\section{ROTEIRO DA ENTREVISTA}

1) Qual(ais) o(s) recurso(s) utilizado(s) na preparação das aulas?

2) $\mathrm{O}(\mathrm{A}) \operatorname{Sr}(\mathrm{a})$ utiliza o livro didático? Qual? Como utiliza?

3) $\mathrm{O}(\mathrm{A}) \operatorname{Sr}(\mathrm{a})$ participou do último processo de seleção do livro didático? Se não, o que acha importante no processo de seleção do livro?

4) O que te levou a selecionar tal livro didático?

5) Sua opção foi baseada em critérios que facilitem a aprendizagem do aluno ou que facilitem a aula?

6) Como foi o processo de seleção do livro didático?

7) Dentre os vários conteúdos apresentados pelo livro didático, existe algum(ns) que o(a) $\operatorname{Sr}($ a) tem dificuldade para a preparação das aulas? Existe(m) algum(ns) motivo(s) para esta(s) dificuldade(s)?

8) E com relação ao aluno, tem dificuldade(s) no aprendizado de algum conteúdo?

9) Como utiliza o livro didático para superar tais dificuldades? Utiliza outros recursos além do livro didático?

\section{DISCURSO PROFESSOR JOÃO CARLOS}

\section{DISCURSO}

PROF. JOÃO CARLOS: Têm conteúdos que não tem nele e a gente tem que trabalhar. E não tem nele. Aí, eu tenho que pesquisar em outro livro. Mas, eu nunca fui de seguir o livro, assim, de A a $Z$ não, ao pé da letra. Eu sempre gosto de pegar atividades de outro livro, sempre estar multiplicando.

\section{UNIDADE DE SIGNIFICADO}

U1: Têm conteúdos que não tem nele e a gente tem que trabalhar. E não tem nele. Aí, tenho que pesquisar em outro livro. Mas, eu nunca fui de seguir o livro assim de $\mathrm{A}$ a $\mathrm{Z}$ não ao pé da letra. Eu sempre gosto de pegar atividades de outro livro. (...) 


\section{DISCURSO PROFESSOR JOÃO CARLOS}

\begin{tabular}{l}
\hline DISCURSO \\
\hline PROF. JOÃO CARLOS: Eu pego mais \\
as atividades do livro didático. Eu procuro \\
fazer um resumo porque não passo, assim, \\
do livro didático. Eu não vou lá passo a \\
passo, igual está no livro não. Eu já faço \\
um resumo daquele conteúdo, passo o \\
meu resumo na lousa. Então, aí... Até esse \\
livro vem assim... Eu no dia em que ele... \\
Eu falei para minha coordenadora: "Cida \\
eu amei o livro!” Porque ele vem e depois \\
no final de cada conteúdo vem um texto. \\
E esse texto vem para interpretar. O texto \\
tem até assim... Qual é a idéia principal do \\
texto. Eu achei ótimo! Só, assim, meio \\
bagunçado. Porque não bateu muito com o \\
referencial. Mas, aí, a gente vai \\
adaptando.
\end{tabular}

PROF. JOÃO CARLOS: O conteúdo que eu mais gosto, que eu tenho mais facilidade é, assim equação. Só que é o conteúdo que os alunos têm mais dificuldade em aprender. E eu já tentei, assim, passar de várias maneiras.

PROF. JOÃO CARLOS: Assim para eles... Não sei qual motivo, se é falta de maturidade também. Às vezes o conteúdo que é dado no sétimo ano, antiga sextasérie... De repente esse conteúdo está muito imaturo para eles, para a idade deles, porque é um conteúdo abstrato.

PROF. JOÃO CARLOS: É! Busco outras coisas, maneiras de passar. Mas é... Às vezes, eu brinco até com eles... É, com frutas, uso frutas para ver se, às vezes, assim, eles entendem na hora. Mas na hora que eles vão para o papel resolver, misturam tudo. Eu não sei... Olha tem dia que eu falo assim: "Olha da vontade de desistir de tudo".

\section{UNIDADE DE SIGNIFICADO}

U2: Eu pego mais as atividades do livro didático. Eu procuro fazer um resumo porque eu não passo, assim, do livro didático. Eu não vou lá passo a passo, igual está no livro. Eu já faço um resumo daquele conteúdo, passo o meu resumo na lousa.

U3: O conteúdo que eu mais gosto, que eu tenho mais facilidade é, assim, equação. Só que é o conteúdo que os alunos têm mais dificuldade em aprender.

U4: Não sei qual motivo, se é falta de maturidade também. Às vezes o conteúdo que é dado no sétimo ano (...) de repente esse conteúdo está muito imaturo para eles, para a idade deles, porque é um conteúdo abstrato.

U5: É! Busco outras coisas, maneiras de passar. (...)eles... É, com frutas (...) eles entendem na hora. Mas na hora que eles vão no papel resolver, misturam tudo.

Às vezes eu brinco até com

\begin{tabular}{|l|l|l|l|l|l|}
\hline Interfaces da Educ. & Paranaíba & v. 2 & n. 5 & p.122-130 & 2011 \\
\hline
\end{tabular}




\section{DISCURSO PROFESSOR JOÃO CARLOS}

\section{DISCURSO}

\section{UNIDADE DE SIGNIFICADO}

PROF. JOÃO CARLOS: Não, geralmente até às vezes. Por exemplo, no livro didático que, às vezes eu tenho até uma crítica... Eles vêm com uma explicação da equação, uma explicação muito complicada. Se você for passar para o aluno vai ser pior que aquele resumo que a gente faz.

PROF. JOÃO CARLOS: Tento outros recursos. Aquilo que eu te falei, eu não fico assim apegada o tempo todo no livro. $\mathrm{Eu}$ uso ele como um recurso para meu auxílio porque eu acho assim... Se a gente ficar, aqui, só em cima do livro, só aqui olha, cinqüenta minutos de aula só com o livro aqui olha... É muito isso daqui... Eu acho que eu tenho que ter uma visão mais aberta, não pode ser como diz: só numa linha reta, ali. Porque esse livro é muito bom, é um conteúdo que eu lhe falo... Eu tenho frustração como diz. Porque eu gosto do conteúdo, eu acho assim... Tenho a maior facilidade e os alunos têm dificuldade.

Prosseguindo com o estudo, partiu-se para a interpretação das unidades de significado, que de acordo com Hiratsuka (2003), é a colocação de forma articulada dessas unidades na linguagem do pesquisador, isto porque ele

\footnotetext{
Almejava pelos seus sentidos originais. Não cabia nenhuma interpretação prévia e, portanto, era necessário estar aberto ao relatado pelo sujeito sobre sua experiência, procurando atentamente fazer com que o que foi dito fizesse sentido para mim. Deveria, então, ser cuidadoso com os significados atribuídos às palavras do depoente. (HIRATSUKA, 2003, p. 72)
}

Posterior à interpretação das unidades de significado, realizou-se as cincos observações das aulas do professor João Carlos, e os dados coletados foram registrados em um caderno de campo. Neste caderno cada um dos pontos anteriormente levantados para a observação eram cuidadosamente registrados. 


\section{Resultados e discussões}

Levando em consideração o embasamento teórico anterior e também, a partir das entrevistas e observações, verifica-se que existe certa lógica entre os pontos apresentados pelos professores durante os depoimentos e a forma com que o livro didático é utilizado em sala de aula; é esta conexão entre o dizer e o fazer do professor de matemática do ensino público de Paranaíba - MS que este estudo propõe-se elucidar.

Nesta perspectiva, este estudo consiste em entender a coerência existente entre, os discursos dos docentes, quanto à utilização do livro didáticos, e a manipulação dos conteúdos apresentados por este livro durante as aulas de matemática, é neste cenário que se insere a figura do professor João Carlos.

Ao acompanhar as aulas deste professor, foram observadas relações entre o que este professor afirma na entrevista e o que acontece em sala de aula quanto à utilização do livro didático. Julgam-se estas relações pertinentes de serem descritas, para que haja entendimento do panorama onde o professor de matemática de Paranaíba está inserido.

Assim, no decorrer das entrevistas o professor João Carlos afirma não utilizar o livro didático nos sétimos anos, pois, muitas vezes, os alunos não estão preparados para receber o conteúdo direcionado a esta série da forma como estão apresentados pelo livro didático, isto porque, trata-se de um conteúdo um pouco mais abstrato. Por esse motivo o professor afirma utilizar resumos de outros livros que venham a facilitar o entendimento do aluno. Entretanto, durante as cinco aulas observadas notou-se, que o livro foi utilizado no sétimo ano. Mostra-se, que isto ocorre devido ao compromisso que o professor assume ao adotar o livro didático, mesmo tendo a autonomia de ministrar suas aulas de acordo com sua concepção esse professor fica preso a este compromisso.

Durante as entrevistas quando questionado sobre a utilização de formas alternativas de ensino do conteúdo para os alunos o professor afirma que busca novas alternativas para instrução da matéria, inclusive trabalhando com situações do dia-a-dia dos alunos, por exemplo: brincando com frutas. Nessas cinco aulas observadas os recursos utilizados pelo professor foram livro didático e quadro negro. Neste eram reproduzidas as atividades propostas pelo livro que por sua vez, sugere a utilização de novos recursos em sala de aula. Entende-se que,

os conteúdos dos livros didáticos só ganham vida quando o professor os toma como meio de desenvolvimento intelectual, quando os alunos conseguem ligálos com seus próprios conhecimentos e experiências, quando através deles aprendem a pensar com sua própria cabeça. (LIBANEO, 2008, p. 78)

Neste prisma, em dado momento da entrevista o professor João Carlos afirma não costumar seguir o livro em sua totalidade, pois, alguns conteúdos exigidos no plano político pedagógico da escola, não são abordados pelo livro didático adotado. Por essa razão o professor procura em outros livros uma correspondência entre conteúdos exigidos pela escola e os tratados no livro didático.

Outro fator presente no depoimento do professor João Carlos, é que, ele busca no livro didático atividades para serem trabalhadas em sala de aula, mas, sem passá-las da maneira como está no livro, antes da aula, ele procura fazer um resumo do conteúdo. E posteriormente, na lousa faz uma prévia do que pretende trabalhar durante a aula, para que os alunos se situem do conteúdo. Segundo Libâneo (2008), "O livro didático é necessário,

\begin{tabular}{|l|l|l|l|l|l|}
\hline Interfaces da Educ. & Paranaíba & v. 2 & n. 5 & p.122-130 & 2011 \\
\hline
\end{tabular}


mas por si mesmo ele não tem vida. É um recurso auxiliar cujo uso depende da iniciativa e imaginação do professor".

$\mathrm{Na}$ entrevista o professor aponta ainda o desinteresse dos alunos como sendo um fator que dificulta a utilização do livro didático em sala de aula. Nas cinco observações realizadas, percebe-se a interferência desse desinteresse no desenvolvimento da matéria durante as aulas em que o livro é utilizado. Ilustrando o descrito neste parágrafo, o professor João Carlos utiliza no sexto ano o livro direcionado para o quinto ano. Quando questionado sobre a razão dessa atitude, o professor afirma que os alunos do sexto ano não têm maturidade e nem interesse de trabalhar com os seus próprios livros, este pode ser um dos motivos para o desinteresse dos alunos.

No entanto, entende-se que, ações que motivem os alunos são necessárias, para que estes vejam a educação, em especial o ensino da matemática, como algo que os prepararão, para a vida profissional e, também, para a sua convivência em meio à sociedade.

Contudo, em relação ao objetivo de verificar as razões das dificuldades que o professor tem de ensinar e/ou o aluno de compreender os conteúdos dos livros didáticos, o trabalho não fornece uma resposta definitiva, mas indícios das razões das dificuldades que o professor tem quanto a utilização do livro didático. Tizzo e Silva (p. 11, 2009) ${ }^{4}$ confirma o que pudemos verificar durante a análise dos dados, ao afirmar que

[...] com base na análise realizada, percebemos que a maioria dos professores tem dificuldade de lidar com situações-problema por não terem desenvolvido habilidades para tanto. Além disso, apesar de reconhecer limitações, a maioria dos entrevistados não traz para si parcela de responsabilidade com relação à dificuldade de aprendizagem do aluno. Chegam a atribuir responsabilidade a outros professores, aos alunos, mas não se incluem. Ainda, considerando que a maioria dos professores entrevistados utiliza o livro didático como referência, chama a atenção não terem enunciado um conteúdo específico (contido no livro) relacionado à dificuldade de ensinar, ou o aluno de aprender.

Com base no exposto até o momento, podemos apontar que as possíveis razões dessas dificuldades podem ser atribuídas ao fato do aluno não ter assimilado conteúdos vistos em anos anteriores, ao pouco tempo que o professor tem para elaborar as atividades, ao fato do aluno não conseguir interpretar textos matemáticos e à resistência do professor à mudanças e a situações novas. Sendo assim, os professores que desejam trabalhar os conteúdos matemáticos a luz do livro didático, necessitam de ações que possibilitem uma reflexão a respeito de seu uso, para minimização dessas dificuldades.

\section{Considerações finais}

Esta pesquisa (qualitativa) desenvolve-se tomando como referência os conteúdos que os professores de matemática da rede de ensino público de Paranaíba - MS têm dificuldade de ensinar, ou o aluno de aprender, a partir das entrevistas e de cinco observações de aula de um desses professores, expõe-se as informações coletadas nas entrevistas e os fatos observados em sala de aula.

\footnotetext{
4 Artigo publicado contendo o relatório das atividades realizadas durante a execução do plano de trabalho: “O professor de matemática e os conteúdos dos livros didáticos”/Iniciação Científica CNPq-PIBIC 2008/09.
}

\begin{tabular}{|l|l|l|l|l|l|}
\hline Interfaces da Educ. & Paranaíba & v. 2 & n. 5 & p.122-130 & 2011 \\
\hline
\end{tabular}


O entendimento da conexão entre o dizer e o fazer do professor, quanto à utilização do livro didático, se faz necessário para a compreensão da lógica existente entre o que o professor afirma fazer e o que acontece em sala de aula. É este cenário que o presente estudo se propôs descrever. Buscou-se, identificar razões, tanto nas entrevistas como nas observações, que justificassem as dificuldades da utilização do livro didático.

Assim, com base nas entrevistas e nas observações, percebe-se que, apesar de os professores não enunciarem um aspecto específico que justifique as dificuldades de utilização do livro didático em sala de aula, eles seguem preparando suas aulas com o auxílio do livro. Logo, acredita-se que essas dificuldades são sanadas através do livro didático.

Concluindo, o professor ao elaborar resumos do livro didático, demonstra um meio criativo de utilização deste, utilizando-o como apoio para a elaboração de seu próprio material de ensino. São esses meios inventivos, que se anseia identificar na prática dos professores de matemática, para em seguida chegar-se a mudanças significativas na educação.

\section{Referências bibliográficas}

HIRATSUKA, P. I. A Vivência da Experiência da Mudança da Prática de Ensino de Matemática. 2003. Tese (Doutorado em Educação Matemática) - Instituto de Geociência e Ciências Exatas, Universidade do Estado de São Paulo, Rio Claro, SP, 2003.

LÜDKE, M.; ANDRÉ, M. E. D. A. Pesquisa em Educação: Abordagens Qualitativas. Editora Pedagógica e Universitária LTDA. São Paulo, 1986.

LIBÂNEO, J. C. Didática. (Coleção magistério. $2^{\circ}$ grau. Série formação do professor). Cortez - São Paulo, 1994.

TIZZO, V. S; SILVA, S. R. V. O professor de matemática e os conteúdos dos livros didáticos. CNPq-PIBIC 2008/09. In: X Encontro de Iniciação Científica UFMS (Cultura e Fronteiras), 2009, Campo Grande. 